\title{
Survey of perceived stress and work demands of consultant doctors
}

\author{
Raymond M Agius, Harriet Blenkin, Ian J Deary, Helen E Zealley, Robert A Wood
}

\begin{abstract}
Objectives-The objectives of this study were to assess the work demands as potential stressors of health service consultants, and to describe the development of tools for measuring stress experiences of consultants.
\end{abstract}

Methods-A stratified random sample of 500 NHS consultants in Scotland was targeted by a postal questionnaire and 375 (75\%) returned a valid response. They completed questionnaires, including information on demographic factors, work demands, occupational stressors, and burnout.

Results-Principal components analysis showed that professional work demands of consultants fell into three categories: clinical, academic, and administrative. Their perceived stressors separated into four main factors: clinical responsibility, demands on time, organisational constraints, and personal confidence. These were assessed by 25 questions in the specialist doctors' stress inventory. Specific questions about perceived stressors which resulted in a high positive response included questions about demands on time, and organisational change in the NHS.

Conclusion-These self reported data characterise and measure the consultants' work demands and their role as potential stressors. These measurements could form the basis for strategies to reduce occupational stress in these workers.

(Occup Environ Med 1996;53:217-224)

Department of Public Health Sciences R M Agius

Department of

Psychology, The

University of

Edinburgh

H Blenkin

I J Deary

Lothian Health

H E Zealley

The Royal College of

Physicians of

Edinburgh

R A Wood

Correspondence to

Dr R M Agius, Department of Public Health Sciences, Medical School, Teviot

Place, Edinburgh EH8 9AG.

Accepted 8 December 1995
Keywords: consultants; stress; burnout

Healthcare workers are prone to stress as well as other occupational health risks, which warrant further epidemiological study. ${ }^{12}$ Medical practitioners experience appreciable stress, ${ }^{3-5}$ comparatively high rates of suicide, ${ }^{34}$ and varying degrees of morbidity and early retirement. ${ }^{6}$ Most of the research on doctors has focused on junior doctors and general practitioners ${ }^{3}$ but consultants as a group ${ }^{7}$ or in various specialties have been shown to be subject to stress. ${ }^{8-10}$ They form a group with special demands as they exercise ultimate independent clinical judgement of the patients under their care, or comparable specialist responsibilities when in non-clinical specialties. They operate against a backdrop of scientific advance, and the introduction of new clinical skills, as well as new managerial demands. Thus for consultants, in common with other health care workers, work "may favour psychic well being" but "may also prove psychically deleterious owing to the individual's own traits, to the working environment, to the nature of the job itself." 4 This may be partly explained by the classification of consultants' jobs as being of high demand and (generally) high decision latitude. ${ }^{11}$ If specific occupational stressors could be identified, corrective strategies might be useful for doctors and patients alike.

Our objectives were firstly to identify, and where necessary develop and devise appropriate self reporting tools for measuring the work demands and stress of consultants, and secondly to apply these tools to find a baseline of important stressors and to study their underlying structure. Reference is made to other reports ${ }^{12} 13$ studying the same sample which deals also with underlying personality traits and coping strategies.

\section{Methods}

GENERAL TOOLS

A literature review did not uncover tools that were adequate and specific on their own to assess the work demands or perceived stressors of NHS consultants but several potential stressors were listed. To assess the relevance of these stressors and to highlight others a qualitative approach was used, and 36 consultants selected from a range of specialties in south east Scotland were invited to attend focused group discussions. Of these 26 took part. They were divided between six groups, each headed by one of the first three authors.

As a result the following questionnaires were devised:

(1) A demographic questionnaire. This requested information including age, sex, marital status, speciality, type of hospital, and years employed. It enquired about the NHS contractual and actual sessional workloads, as well as non-NHS sessions.

(2) The consultants work demands scale. This was assessed through visual analogue responses to information about the characteristics of the consultants' work demands. As the job title and department alone were not considered adequate descriptions of the nature of the work and hence of the exposures under study, it asked about differential aspects of the actual work. This would enable, through 
Table 1 Mean (SD) responses to the consultant work demands scale

\begin{tabular}{|c|c|c|c|}
\hline $\begin{array}{l}1 \\
2 \\
3\end{array}$ & $\begin{array}{l}\text { No clinical duties } \\
\text { No patient contact } \\
\text { No physically invasive procedures }\end{array}$ & $\begin{array}{l}8 \cdot 04(2 \cdot 93) \\
5 \cdot 78(2 \cdot 73) \\
5 \cdot 10(3 \cdot 32)\end{array}$ & $\begin{array}{l}\text { Full time clinical duties } \\
\text { Operating theatre or intensive care } \\
\text { Predominantly highly invasive } \\
\text { procedures }\end{array}$ \\
\hline 4 & No direct clinical responsibility & $7.59(3.57)$ & $\begin{array}{l}\text { All patients are direct clinical } \\
\text { responsibility }\end{array}$ \\
\hline 5 & All work routine and scheduled & $5.09(2.07)$ & $\begin{array}{l}\text { All clinical work emergency and } \\
\text { unscheduled }\end{array}$ \\
\hline $\begin{array}{l}6 \\
7\end{array}$ & $\begin{array}{l}\text { Untrained newly registered staff } \\
\text { No teaching responsibilities }\end{array}$ & $\begin{array}{l}5 \cdot 67(2 \cdot 67) \\
4 \cdot 85(2 \cdot 43)\end{array}$ & $\begin{array}{l}\text { Staff well trained and accredited } \\
\text { Full time academic teaching } \\
\text { responsibilities }\end{array}$ \\
\hline $\begin{array}{l}8 \\
9\end{array}$ & $\begin{array}{l}\text { No research responsibilities } \\
\text { No administrative duties }\end{array}$ & $\begin{array}{l}3.56(2.48) \\
5.33(2 \cdot 30)\end{array}$ & $\begin{array}{l}\text { Full time research responsibilities } \\
\text { Full time administrative duties }\end{array}$ \\
\hline
\end{tabular}

established psychometric statistical methods described later, the derivation of types of work demands (factors), which could then be related to health outcomes. The items in the consultant work demands scale included the extent of patient contact, involvement in physically invasive procedures, direct clinical responsibility for patients, and routine versus

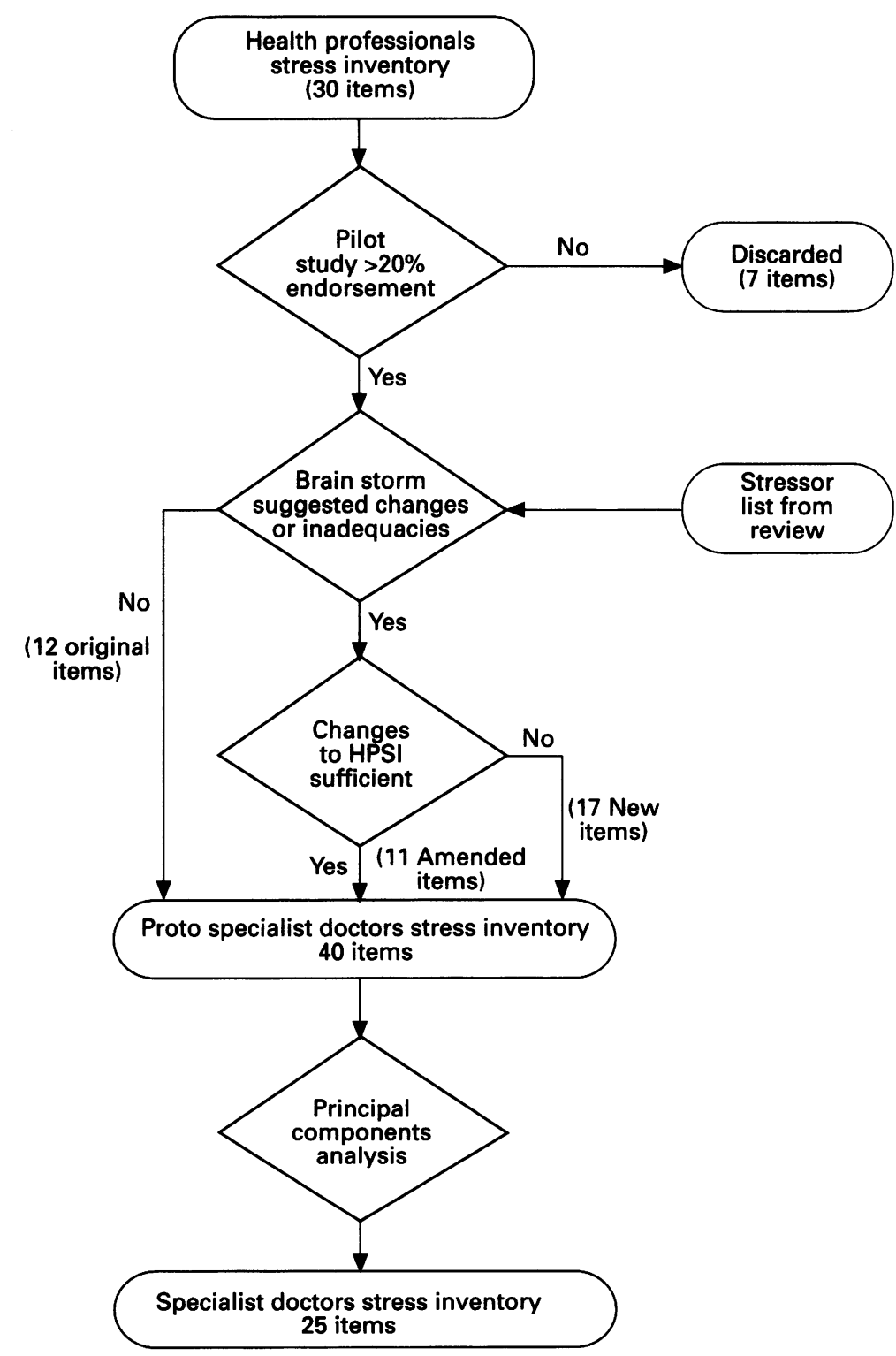

Flow diagram showing the method of derivation of the 25 item specialist doctors stress inventory. HPSI = health professional stress inventory. emergency work. The consultant work demands scale also included questions on the level of training of the most senior regular supporting staff, and non-clinical duties, specifically teaching, research, and administration. Table 1 shows the "poles" for each of the nine items on the 10 point visual analogue scale: for example a consultant neurosurgeon who had an accredited senior registrar might be expected to circle 10 or close to it for items 3 and 6.

(3) The specialist doctors stress inventory (SDSI). Review of the literature identified the 30 item health professionals stress inventory ${ }^{14}$ which had been validated for other categories of healthcare workers. However, this, and other validated tools, were too broadly based to be ideal for NHS consultants. Therefore the focused groups already described were used to adapt the health professionals stress inventory into a proto-SDSI in three ways.

Firstly, consultants made lists of their common stressors and these were developed in brainstorming sessions. Secondly, consultants in the focused groups were shown a checklist of putative stressors (compiled from a literature review) and asked to endorse those which they found to be stressors in their own work. Thirdly, they completed the health professionals stress inventory. The figure shows the development of the proto-SDSI from the health professionals stress inventory in a simplified form. Briefly, those items in the health professionals stress inventory and those from the literature review checklist with a positive endorsement of less than $20 \%$ were removed. The remaining health professionals stress inventory items were amended where indicated by the consultants' comments. Additional stressors identified as important in the brainstorming including those relating to organisational change in the NHS, and some from the stressor review checklist were therefore added. This resulted in a 40 item protoSDSI containing 12 unchanged and 11 amended health professionals stress inventory items, and 17 new items. The original response format based on frequency in the health professionals stress inventory (neververy often) was amended as a consequence of the focused group sessions so that the participants could indicate the magnitude of the contribution of each item to their overall stress level $(0=$ no contribution to $4=$ big contribution). This response format was intended to measure the strain caused by the stressor and not merely the frequency of the stressor. It is therefore analogous to a product of the likelihood of response to, and the effect of, the stressor on the individual consultant. The reduction of this questionnaire after principal component analysis to a recommended 25 item format SDSI is described in the results section below.

(4) Previously validated questionnaires. The Maslach burnout inventory consisting of 22 questions on a six point scale was applied to measure the three dimensions of burnout ${ }^{15}$. emotional exhaustion (feelings of emotional and psychological overextension); depersonali- 
sation (treating patients as impersonal objects); and (lack of) personal accomplishment (having negative attitudes about oneself particularly with respect to competence and successful achievement in one's work). Other questionnaires also included were: the 28 question version of the general health questionnaire ${ }^{16}$; the 48 item coping inventory for stressful situations ${ }^{17}$; the 60 item NEO five factor inventory. ${ }^{18}$ However, limited results from the Maslach burnout inventory only are presented here, as investigation of underlying personality, of coping strategies, and of general (mental) health are the subject of other reports. ${ }^{45}$

\section{SAMPLING}

Reference was made to a sampling frame covering all health service consultants in Scotland-namely, the database kept for the purposes of the distinction awards system. A total of 2442 consultants in non-locum employment were thus identified. For the purposes of this study 48 clinical and eight community categories were reduced to eight major categories of activity. One hundred consultants were randomly selected in medicine, and in surgery; and 50 each in anaesthetics, obstetrics and gynaecology, psychiatry, public health, radiology and pathology and other laboratory specialties. The study excluded 17 consultants in small unique specialties such as occupational medicine, as well as those who had participated in the focused groups.

\section{POSTAL QUESTIONNAIRE}

These 500 randomly selected consultants were sent a package of these questionnaires, together with covering explanatory letters from the research team and from the Dean of the Royal College of Physicians of Edinburgh indicating the support of this college and of sister colleges and faculties. The packages were sent to the home addresses that appeared in the medical register, and were delivered the day before a bank holiday weekend. This was followed, in the case of non-responders, 14 days later by a short letter encouraging response, which was sent to the work addresses. Finally those consultants who had still not responded were sent a further package of questionnaires and covering letters 28 days after the original package to their work addresses.

\section{DATA HANDLING AND STATISTICAL ANALYSIS}

In the data entry and analysis, the data files from the returned questionnaires did not include the identity of the individual responders. Data were entered on an Apple Macintosh LCII 4/40 into Microsoft Excel version 4.0 (spreadsheet). From there it was transferred to the statistical package for social sciences (SPSS 4.0 ) for statistical analysis. Questionnaires that had two or more responses missing were excluded as these could have hindered or biased the subsequent analysis. Where only one response was missing from the proto-SDSI, the response was given the mean value of the other 39 values. A simi- lar procedure was followed for the Maslach burnout inventory questionnaire but values were added for each factor rather than for the questionnaire as a whole. Cronbach's coefficient $\alpha$ was used to measure reliabilitynamely, a measure of internal consistency of the multiple item scales or factors. Principal components analysis with Varimax rotation (SPSS) was applied to the responses in the SDSI, with further manoeuvres to eliminate redundant questions and reduce the number of factors while accounting for as much of the variance as possible.

\section{Results}

RESPONSE

Of the 500 sets of questionnaires posted, three were returned by the postal service as undelivered and one doctor incorrectly included in the sampling frame was excluded from the study, thus leaving a sample of 496 . Out of these, $407(82 \cdot 1 \%)$ sets of questionnaires were returned. However as some were incomplete or received after the analysis had begun, this left a total of 375 usable questionnaires returned within nine weeks of the first posting date. There were no significant differences in the response rates among the eight specialties.

\section{DEMOGRAPHY AND TIME WORKED}

The mean (SD, range) age of the respondents was $46.3(7 \cdot 4,32-65)$ years. They had been working as consultants for $10 \cdot 8(7 \cdot 0,0 \cdot 5-30)$ years, with a mean of 9.4 years in their current post. Of the 374 respondents to the relevant question $302(81 \%)$ were men. Of the 338 respondents to the relevant question 216 $(64 \%)$ worked in a teaching hospital.

The median number of sessions (notional half days) contracted or actually worked each week for the NHS was 11 for the whole group. Most of the respondents did not engage in non-NHS salaried work-for example, for a University - and undertook no private work or less than one weekly session. The overall means (SDs) of weekly sessions devoted to these activities were $0.92(2.30)$ and 0.32 $(0.64)$ respectively.

\section{CONSULTANT WORK DEMANDS SCALE}

Of the nine items of the consultants work demands scale, the highest mean score on the 10 point scale was for the amount of clinical work, and the lowest was for the amount of research work done (table 1 ). The nine items of the consultants work demands scale were further analysed for correlation and this showed that the five items on clinical duties (numbered 1 to 5 ) were significantly correlated. There were also significant, but generally weaker, correlations between the other four items, but as one of these (administration) had the lowest loading on either factor $(<0.45)$ it was considered separately. Principal components analysis showed that three component factors accounted for $34.7 \%$ of the total variance. Varimax rotation of the three factor solution was used to provide three scales. These were: clinical (five items), acade- 
Table 2 Principal components analysis of consultant work demands scale (SPSS 4.0, Varimax Rotation, criteria for inclusion into factor loading $\geqslant 0.45$

\begin{tabular}{llrr}
\hline & & $\begin{array}{c}\text { Factor 1 } \\
\text { (clinical) }\end{array}$ & $\begin{array}{r}\text { Factor 2 } \\
\text { (academic) }\end{array}$ \\
\hline 1 & Clinical duties & $\mathbf{0 . 8 0 8}$ & -0.203 \\
2 & Patient contact & $\mathbf{0 . 8 7 2}$ & -0.131 \\
3 & Physical invasion & $\mathbf{0 . 7 4 9}$ & 0.015 \\
4 & Clinical responsibility & $\mathbf{0 . 8 2 1}$ & -0.174 \\
5 & Routine or emergency & $\mathbf{0 . 4 7 0}$ & 0.100 \\
6 & Staff training & -0.040 & 0.494 \\
7 & Teaching & 0.147 & $\mathbf{0 . 8 4 8}$ \\
8 & Research & -0.074 & $\mathbf{0 . 8 5 3}$ \\
9 & Administration & -0.253 & 0.426 \\
\hline
\end{tabular}

mic (three items), and administrative (one item). Table 1 shows the items comprising these factors which are listed as $1-5,6-8$, and 9 , respectively. All items had a loading of $\geqslant 0.45$ on their respective scales (table 2). The Cronbach $\alpha$ for the clinical and academic factors was 0.81 and 0.62 , respectively. This justified the pooling of these items into these three sets as putative exposure variables for the purposes of correlation with the three Maslach burnout inventory outcome variables as described later.

\section{SPECIALIST DOCTORS STRESS INVENTORY}

Table 3 shows the three items with the highest and the three items with the lowest positive responses out of the 40 item proto-SDSI as sent to the respondents. Table 3 summarises what situations were perceived to contribute most, or least, to the overall stress level of the responding consultants. This is expressed as positive endorsement (percentage scoring 1 or higher) and as mean response (assuming a linear weighting on the five point: $0-4$ scale).

Although this questionnaire (in common with most of the others used) seemed to ask about many separate variables in each consultant, the actual numbers of distinct latent characteristics under study is presumed to be small. Moreover further analysis was required to find which questions might be sensibly combined, which were made redundant by the others, and which were too diffuse to be of much value. The responses to the 40 items of the proto-SDSI were therefore first subjected to principal components analysis. Inspection of the first unrotated principal component indicated the presence of a general stress factor accounting for $25.6 \%$ of the total variance on which all items loaded at a level greater

Table 3 Highest and lowest responses (by \% positive endorsement $\geqslant 1$ and mean) to the 40 item proto-SDSI analysis); preamble: "The following statements reflect possible stressful situations encountered by consultants in the course of their work. Please indicate to what extent each of these situations contributes to your own stress level by circling a number from $0-4$ "

\begin{tabular}{llll}
\hline $\begin{array}{l}\text { Rank of } \\
\text { endorsement }\end{array}$ & Statement & $\begin{array}{l}\text { Endorsement } \\
\text { (\%) }\end{array}$ & $\begin{array}{l}\text { Mean } \\
\text { response }\end{array}$ \\
\hline 1 & $\begin{array}{l}\text { Having so much work to do that everything cannot } \\
\text { be done well } \\
\text { Being interrupted by phone calls or people when } \\
\text { performing job duties }\end{array}$ & 97.8 & 2.74 \\
2 & $\begin{array}{l}\text { Coping with the extra workload resulting from } \\
\text { changes in the NHS }\end{array}$ & 93.8 & 2.28 \\
3 & $\begin{array}{l}\text { Allowing personal feelings or emotions to interfere } \\
\text { with the care of patients }\end{array}$ & 93.5 & 2.60 \\
38 & $\begin{array}{l}\text { Feeling that opportunities for advancement on the } \\
\text { job front are poor }\end{array}$ & 54.3 & 0.76 \\
40 & Having to inflict pain on patients & 48.4 & 0.83 \\
40 & & 47.3 & 0.76 \\
\hline
\end{tabular}

than 0.39 . Therefore a consultant who indicated that any one item made a big contribution to his or her stress level was more likely to indicate that another item also made a big contribution. Nine items with eigenvalues $>1$ emerged which accounted for $59 \%$ of the variance. To simplify the solution further, analyses taking account of item response characteristics were carried out. Items with a loading of 0.4 or more on only one factor were included whereas items with a loading of 0.4 or more on more than one factor-that is, which were not very specific-were excluded. However, the total number of items affecting any one factor was also considered. Thus some items which would have been excluded with the other criteria were retained if they had a particularly high percentage endorsement rate or if they loaded on a factor which otherwise would have had only a few items affecting it. The solution presented here is a principal components analysis with "oblimin" oblique rotation. This analysis when applied to 25 of the 40 items resulted in a four factor solution in which only two items had more than one loading in excess of 0.3 - that is, most were very specific to the oblique factors to which they were principally assigned. Table 4 shows the 25 items in the SDSI scale (reduced from the 40 item protoSDSI). The first unrotated principal component (the general stress factor) accounted for $24.5 \%$ of the total variance, and the four obliquely rotated components together accounted for $47.6 \%$ of the total variance. Table 4 shows the loadings of each of the items on the first unrotated principal component, each of the four rotated factors, the responses on percentage, and mean endorsement of the perceived stressors from the 25 items.

Factor 1 was clinical responsibility (Cronbach $\alpha$ 0.85, mean response 1.50). Eight items with moderately high and very specific loadings of $\geqslant 0.53$ were found to affect this first rotated factor which related to consultants' concerns about their patients' care, their feelings of responsibility for its outcome, and other clinical concerns.

Factor 2 was demands on time (Cronbach $\alpha: 0 \cdot 66$, mean response $2 \cdot 26$ ). Five items with relatively high and specific loadings of $\geqslant 0.51$ affected factor 2 . This factor related to the pressure and conflict in trying to balance and compromise between competing time demands such as clinical practice, report writing, administration, and family commitments. All questions had endorsements $>85 \%$ and this factor had the highest mean response.

Factor 3 was organisational constraints (Cronbach $\alpha 0.73$, mean response 2.09). This factor was affected by four items all of which loaded at a level of $\geqslant 0.56$ and considered stressors associated with lacking organisational resources, and conflict between professionals in carrying out the job in the way respondents thought appropriate.

Factor 4 was personal confidence (Cronbach $\alpha 0.76$, mean response 1.39). Eight items loaded at a level $\geqslant 0.45$ on this factor which reflected concerns about main- 
Table 4 Analysis of the SDSI showing the items tabulated under the factors which each indexed

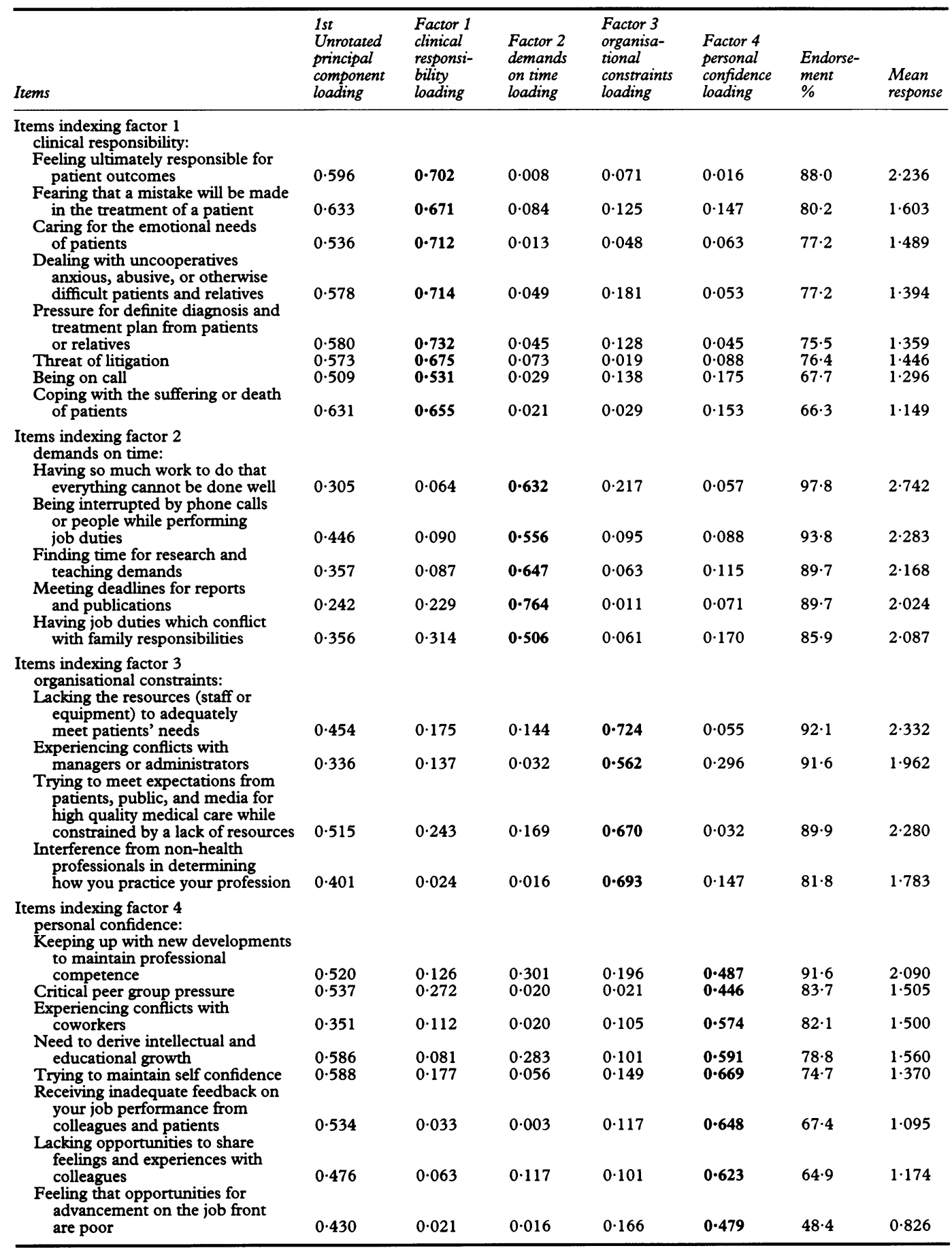

taining personal professional competence as judged by peers and others, self confidence, and career prospects.

Assuming equivalence of each of the items in the 25 item SDSI and linear weighting of the scores, the mean stress score for the consultants was $42 \cdot 84$ out of a total possible score of $100(25 \times 4)$.

\section{CORRELATIONS WITH BURNOUT}

Table 5 summarises the correlation coefficients between relevant demographic variables and the three outcomes from the Maslach burnout inventory-namely, depersonalisation, emotional exhaustion, and personal accomplishment. Table 5 also shows the correlation between the demographic variables and the overall mean responses, as well as each of the four factors of the 25 item SDSI. It shows that there are inverse (favourable) significant relations between age, or years as a consultant, and the two adverse variables, depersonalisation and emotional exhaustion, from the Maslach burnout inventory as well as the SDSI total score. There are small but significant positive correlations between the total number of NHS sessions (actual or contracted) and the two unfavourable dimensions of burnout (depersonalisation and emotional exhaustion) as well as the clinical responsibility factor of the SDSI. However, the number of other non-NHS salaried sessions significantly correlated inversely (favourably) with these adverse variables. 
Table 5 Matrix of correlation coefficients showing the degree of association between some demographic variables, and outcomes of Maslach burnout inventory (MBI) and the overall mean as well as the four factors of the 25 item SDSI

\begin{tabular}{|c|c|c|c|c|c|c|c|c|}
\hline \multirow[b]{2}{*}{$\begin{array}{l}\text { Demographic } \\
\text { variables }\end{array}$} & \multicolumn{3}{|l|}{$M B I$} & \multicolumn{5}{|l|}{ SDSI } \\
\hline & $\begin{array}{l}\text { Deperson- } \\
\text { alisation }\end{array}$ & $\begin{array}{l}\text { Emotional } \\
\text { exhaustion }\end{array}$ & $\begin{array}{l}\text { Personal } \\
\text { accomplish- } \\
\text { ment }\end{array}$ & Overall & $\begin{array}{l}\text { Clinical } \\
\text { responsib- } \\
\text { ility }\end{array}$ & $\begin{array}{l}\text { Demands } \\
\text { on time }\end{array}$ & $\begin{array}{l}\text { Organisa- } \\
\text { tional } \\
\text { constraints }\end{array}$ & $\begin{array}{l}\text { Personal } \\
\text { confidence }\end{array}$ \\
\hline Age & $-0 \cdot 152^{\star \star}$ & $-0 \cdot 129^{\star}$ & -0.017 & $-0 \cdot 175^{\star \star}$ & $-0 \cdot 102$ & -0.048 & -0.053 & -0.014 \\
\hline consultant & $-0 \cdot 104^{\star}$ & $-0 \cdot 145^{\star}$ & -0.063 & $-0 \cdot 162$ & -0.041 & -0.059 & -0.027 & -0.024 \\
\hline $\begin{array}{l}\text { sessions } \\
\text { Contracted NHS }\end{array}$ & $0 \cdot 140^{\star}$ & $0 \cdot 177^{\star \star}$ & 0.045 & $0 \cdot 261^{\star \star}$ & $0 \cdot 218^{\star \star}$ & 0.080 & 0.055 & 0.003 \\
\hline $\begin{array}{l}\text { sessions } \\
\text { Other (non-NHS) }\end{array}$ & $0 \cdot 164^{\star \star}$ & $0.193^{\star \star}$ & 0.045 & $0 \cdot 217^{\star \star}$ & $0 \cdot 210^{\star \star}$ & 0.079 & 0.042 & 0.075 \\
\hline $\begin{array}{l}\text { salaried sessions } \\
\text { Private sessions }\end{array}$ & $\begin{array}{l}-0 \cdot 152^{\star \star} \\
-0 \cdot 110^{\star}\end{array}$ & $\begin{array}{l}-0.112^{\star} \\
-0.088\end{array}$ & $\begin{array}{r}-0.095 \\
0.090\end{array}$ & $\begin{array}{l}-0.160^{\star \star} \\
-0.049\end{array}$ & $\begin{array}{l}-0.208^{\star \star} \\
0.049\end{array}$ & $\begin{array}{r}0.042 \\
-0.040\end{array}$ & $\begin{array}{l}-0.067 \\
-0.015\end{array}$ & $\begin{array}{r}-0.053 \\
0.028\end{array}$ \\
\hline
\end{tabular}

Table 6 Matrix of correlation coefficients between the three factors of the consultant work demands scale as putative exposure variables against the outcomes of Maslach burnout inventory (MBI) and the overall mean as well as the four factors of the 25 item SDSI

\begin{tabular}{|c|c|c|c|c|c|c|c|c|}
\hline \multirow[b]{2}{*}{ Work demands } & \multicolumn{3}{|l|}{$M B I$} & \multicolumn{5}{|l|}{$S D S I$} \\
\hline & $\begin{array}{l}\text { Deperson- } \\
\text { alisation }\end{array}$ & $\begin{array}{l}\text { Emotional } \\
\text { exhaustion }\end{array}$ & $\begin{array}{l}\text { Personal } \\
\text { accomplish- } \\
\text { ment }\end{array}$ & Overall & $\begin{array}{l}\text { Clinical } \\
\text { responsib- } \\
\text { ility }\end{array}$ & $\begin{array}{l}\text { Demands } \\
\text { on time }\end{array}$ & $\begin{array}{l}\text { Organisa- } \\
\text { tional } \\
\text { constraints }\end{array}$ & $\begin{array}{l}\text { Personal } \\
\text { confidence }\end{array}$ \\
\hline $\begin{array}{l}\text { Clinical } \\
\text { Academic } \\
\text { Administrative }\end{array}$ & $\begin{array}{c}-0.035 \\
-0.134^{\star} \\
0.028\end{array}$ & $\begin{array}{c}0.015 \\
-0.139^{\star} \\
0.048\end{array}$ & $\begin{array}{l}0.268^{\star \star} \\
-0.003 \\
-0.062\end{array}$ & $\begin{array}{c}0 \cdot 220^{\star} \\
-0.125^{\star} \\
0.045\end{array}$ & $\begin{aligned} & 0.471^{\star \star} \\
-0.184^{\star \star} & -0.048\end{aligned}$ & $\begin{array}{l}-0.014 \\
0.053 \\
0.215^{\star \star}\end{array}$ & $\begin{array}{l}0 \cdot 128^{\star} \\
0.010 \\
0.071\end{array}$ & $\begin{array}{c}-0.071 \\
-0.073 \\
0.124^{\star}\end{array}$ \\
\hline
\end{tabular}

$\star P<0.05 ; \star \star P<0.01$.

Table 6 shows the correlations between the three factors of the consultants work demands scale, and each of the four factors of the SDSI, and the three outcome variables of the Maslach burnout inventory, and the mean responses. These correlation coefficients show that there is a positive association between the one favourable dimension of burnout (personal accomplishment) and clinical work demands. There is also a significant, albeit weaker (but favourable), inverse correlation between academic work demands and the unfavourable burnout dimensions of depersonalisation and emotional exhaustion as well as the perceived stress from clinical responsibility. Clinical work demands correlate positively (unfavourably) with perceived stress from the factors of clinical responsibility and organisational constraints, whereas administrative work demands correlate with the other two stress factors (demands on time and personal confidence).

\section{Discussion}

This study provides useful new data on the workload characteristics of consultants in the NHS in Scotland, of consultants' perceived stressors, and their underlying structure. Furthermore it permits these exposure variables to be analysed in relation to personality and other factors. ${ }^{45}$ The relatively high response rate, perhaps due to strong college support as well as self interest among consultants, lends confidence to the interpretation of the results and compares well with overall response rates that range from $43 \%$ to $79 \%$ in other relevant studies of doctors. ${ }^{27-10121920}$ Non-response bias was therefore likely to be small, but one could speculate whether the consultants with more demands on their time might have been less likely to respond. This study began with focused group exercises to permit it to consider specifically the perceived stressors of this particular group of health care workers. In common with many other studies of occupational stress ${ }^{21}$ the quantitative aspect of the work was cross sectional and reliant on self reporting both for measures of exposure and of response. Therefore it lacked triangulation by not having an independently measured variable to validate either or both of these measures. ${ }^{22}$

The responses to the consultants work demands scale indicated that there are three main professional directions to the consultants' work-clinical duties that are directly related to patient care, academic (teaching and research in nature), and administrative. This scale can find further useful application in characterising the components of consultants' work and therefore their exposure in a manner which transcends the specific department or setting. Use of such a scale may therefore permit study of the underlying exposure variables and add to the methods which compare stress between categories classified by job title. ${ }^{61013}$ However, this scale may require further refinements in terms of item content and predictive validity, especially for administration, which at present is only affected by one item.

Although these components of the consultant work demand scale can be correlated with adverse outcome variables such as burnout (discussed later), they do not identify specific aspects of the work which may be stressful and yet perhaps amenable to intervention. For this purpose, the measurement of stressors through a self reported stress inventory uses a principal components approach in the study of occupational stress. After principal components analysis the 40 item proto-SDSI has been reduced to the 25 item SDSI. This final version has the merit of being shorter than the health professionals stress inventory ${ }^{14}$ and especially of being tailored to consultant doc- 
tors. It is well recognised that various qualitative and quantitative aspects of the work of health care workers are important stressors. ${ }^{23}$ Principal components analysis of the SDSI provides a much more sophisticated approach to studying the perceived stressors of consultants than merely considering the endorsement rate of the individual questions or a mean score of a series of items as it identifies fundamental latent characteristics of their stresses. The four factors described here account for about half the total variance between items.

The first of these factors relates to clinical responsibility as the nature of the work of consultants is such that it is always likely to present significant potential for stress, but the data show a lower level of mean endorsement than the demands on time factor discussed next. Thus although prospects for stress reduction arising from clinical responsibilities in the clinical specialties should not be discounted, they are clearly limited.

On the other hand, the second and third factors, demands on time and organisational constraints corroborate the impression gained from a simple comparison of endorsement of individual questions. Thus the two questions with the highest endorsement rate (table 3) affected the second factor, demands on time, (table 4) and indicated that consultants, in common with other physicians, ${ }^{24}$ find this to be an important stressor. This high positive response may have an important contribution from the high perception that these professionals have of the quality of work that is expected of them (table 3 ). However it should be noted that the third highest endorsed question (table 3) relates to organisational change, which is also reported to have increased job stress among general practitioners. ${ }^{25}$ These findings corroborate, more specifically in relation to health service consultants, the findings of others ${ }^{51926}$ that a work overload and interruptions at work as well as organisational constraints, are important work stressors. The challenge is therefore to find ways of supervising and measuring the work of consultants while giving them adequate job decision latitude $^{11}$ and balance of their workload within a framework of assessing and controlling the risks to their health. ${ }^{19}$

The fourth stress factor is related to personal confidence. Although consultants as a group did not experience a large contribution to their levels of stress from a lack of opportunities for career advancement, the items loading on this factor could clearly distinguish the subjective experiences of individual consultants. Indeed this factor exemplifies the importance of differentiating between those items which are perceived overall as most stressful, and those stressors or manifestations of stress among which there are the largest individual differences. In summary, the four factors described here should be useful measurements of the different patterns of stress arising in this special occupational group as a result of the interaction between the work environment and the individual consultant. ${ }^{12}$
The 25 question SDSI can be reproduced by use of the preamble heading for table 3 followed by the items (in random order) in table 4. (The choice of numbers was from 0-4.)

Burnout has been the subject of several definitions but is characterised by "progressive loss of idealism, energy, and purpose experienced by people working in the human services." 27 A high level of burnout features higher scores for emotional exhaustion and depersonalisation and lower scores for personal accomplishment. ${ }^{15}$ The mean scores for the burnout in consultants in this study were similar to those for the general population and for the medical profession as a group. ${ }^{13}$ Although this finding may reflect the consultants' psychological strengths, the potential impact of the stressors on vulnerable personalities must not be overlooked. ${ }^{12}$ The results in table 5 suggest that age, years as a consultant, and number of other salaried sessions worked (mainly University employment) are negatively associated with the unfavourable aspects of burnout. One explanation is that increasing age or time as a consultant are protective, but the findings could also be the result of the cross sectional nature of the study which has investigated a survivor population. ${ }^{21}$ The implication of this second interpretation is that people who are more vulnerable to stress might have changed career during their higher specialist training or retired early in their consultant employment. (A study on retired consultants is being completed and will be reported later.) The significant correlation between the number of actual or contracted NHS sessions and burnout as well as the mean SDSI score supports a causal relation between quantitative workload and stress but needs to be cautiously interpreted in the light of further study. Thus clinical work demands might be protective insofar as they are correlated with a higher degree of personal accomplishment. In a study of emergency physicians, who have intensive clinical demands, personal accomplishment levels were high, but so was depersonalisation. ${ }^{9}$ Academic work demands (table 6), as well as non-NHS salaried sessions (table 5), correlated significantly and inversely with depersonalisation and emotional exhaustion as well as with the clinical reponsibility factor of the SDSI. This suggests that academic work may be associated with less stress and burnout than clinical work but honorary (academic) staff have also been shown to have different personality behaviour patterns. ${ }^{8}$

Further evidence, including the role of personality, coping strategies, and other variables in explaining the complex pathways linking consultants' work with stress, is presented elsewhere. ${ }^{12}$ Although cross sectional studies of this nature can, and have, identified important perceived stressors on the quantitative and qualitative aspects of the work demands of consultants, including those associated with organisational change, care must be applied in interpreting the results, and prospective research needs to be conducted with the tools described here and similar ones.

In conclusion, this work has shown that it is 
feasible, through self reporting, to measure the various dimensions of the work demands, and perceived occupational stressors of consultant doctors. It contributes to the acknowledged need for more research into the measurement of the experience of stress and the overall stress process ${ }^{22}$ in a small, but important and distinctive, category of workers. The four factors named, clinical responsibility, demands on time, organisational constraints, and personal confidence, should each be amenable, albeit to varying degrees, to strategies to reduce exposure to potentially harmful stressors by influencing the control cycle. ${ }^{22}$

The sponsorship and support of the Royal College of Physicians of Edinburgh including the contribution of the MacDonald Bequest is most gratefully acknowledged. Our thanks also go to the other colleges and faculties whose support and endorsement helped in the favourable response to the study. We thank the Information and Statistics Division of the Management Executive of the National Health Service in Scotland for providing the sampling frame. Finally we thank all the consultants who gave their time in responding to the questionnaires, and especially to those who participated in the focused groups.

1 Harrington JM. The health of health care workers. $f$ R Coll Physicians Lond 1990;24:189-95.

2 Rees D, Cooper CL. Occupational stress in health service workers in the UK. Stress Medicine 1992;8:79-90

3 British Medical Association. Stress and the medical profession. London: BMA, 1992.

4 Gestal JJ. Occupational hazards in hospitals: accidents, radiation, exposure to noxious chemicals, drug addiction and psychic problems, and assault. $\mathrm{Br} \mathcal{F}$ Ind Med. 1987; 44:510-20.

5 Burke RJ, Richardsen AM. Sources of satisfaction and stress among Canadian physicians. Psychol Rep 1990;67: stress am

6 McNamee R, Keen RI, Corkill CM. Morbidity and early retirement among anaesthetists and other specialties. Anaesthesia 1987;42:133-40.

7 Caplan RP. Stress, anxiety, and depression in hospital consultants, general practitioners, and senior health service managers. $B M F$ 1994;309:1261-3.

8 Green A, Duthie HL, Young HL, Peters TJ. Stress in surgeons. Br ₹ Surg 1990;77:1154-8.

9 Keller KI, Koenig WJ. Management of stress and prevention of burnout in emergency physicians. Ann Emerg Med tion of burnout in

10 Whippen DA, Canellos GP. Burnout syndrome in the practice of oncology: results of a random survey of 1000 oncologists. F Clin Oncol 1991;9:1916-20.

11 Karasek RA. Job demands, job decision latitude and mental strain. Implications for job redesign. Administrative Science Quarterly 1979;24:285-308.

12 Deary IJ, Blenkin H, Agius RM, Endler NS, Zealley H, Wood RA. Models of job-related stress and personal achievement among consultant doctors. $\mathrm{Br} f$ Psychol 1996;87:3-29.

13 Blenkin H, Deary IJ, Wood RA, Zealley H, Agius RM. Stress in NHS consultants. BMF 1995;310:534

14 Wolfgang A P. Job stress in the health professions: a study of physicians, nurses and pharmacists. Behav Med 1988;14: 43-7.

15 Maslach C, Jackson SE. Maslach burnout inventory manual; 2nd ed. Palo Alto, California: Consulting Psychologists Press, 1986.

16 Goldberg D, Williams P. A user's guide to the general health questionnaire. Windsor: NFER Nelson, 1988.

17 Endler NS, Parker JDA. Coping inventory for stressful situations (CISS) manual. Toronto: Multi-Health Systems, tions 1990 .

18 Costa PT, McCrae R. NEO PI-R professional manual; revised NEO personality inventory (NEO-PI-R) and NEO five-factor inventory (NEO-FFI). Odessa, Florida: Psychological Assessment Resources, 1991.

19 Cooper CL, Rout U, Faragher B. Mental health, job satisfaction, and job stress among general practitioners. $B M \mathcal{F}$ 1989;298:366-70.

20 Jex SM, Hughes P, Storr C, Baldwin DC, Conard S. Behavioural consequences of job related stress among resident physicians: the mediating role of psychological strain. Psychol Rep 1991;69:339-49.

21 Kalimo R. Assessment of occupational stress. In: Karvonen M, Mikheev MI, eds. Epidemiology of occupational health. M, Mikheev MI, eds. Epidemiology of occupational health.

22 Cox T. Stress research and stress management: putting theory to work. Sudbury: Health and Safety Executive Books, 1993. (Contract Research Report No 61.)

23 Leppanen RA, Olkinoura MA. Psychological stress experienced by health care personnel. Scand $¥$ Work Environ Health 1987;13:1-8.

24 Mawardi BH. Satisfactions, dissatisfactions and causes of stress in medical practice. $\mathcal{F} A M A 1979 ; 241: 1483-6$.

25 Sutherland VJ, Cooper CL. Job stress, satisfaction and mental health among general practitioners before and mental health among general practitioners before and after in $1545-8$.

26 Simpson LA, Grant L. Sources and magnitude of job stress among physicians. $\mathcal{F}$ Behav Med 1991;14:27-42.

27 Hare J, Pratt CC, Andrews D. Predictors of burnout in professional and para-professional nurses working in hospitals and nursing homes. Int $\mathcal{F}$ Nurs Stud 1988;25: 105-15.

\section{Occupational and Environmental Medicine and the electronic age}

OEM has an Email address which is 100632.3615@compuserve.com.We welcome contact by Email, including letters to the editor. Some of our reviewers already send us their reports by Email, helping to speed up the peer review process.

We are moving towards electronic publishing and for some months now we have been asking authors to send us their revised papers on disk as well as a hard copy. I am delighted to report that nearly all our authors are managing to comply with this request; far more than for other specialist journals in the BMJ Publishing group. Oddly enough, the few authors who have not sent us a disk version of their revised papers have been almost exclusively from the United Kingdom. I would be interested in suggestions for why this might be. Perhaps United Kingdom based authors read our correspondence and instructions less assiduously? Watch for revised Instructions to Authors.

The Editor 